\title{
Ultrasound conditioning of Streptococcus thermophilus CNRZ 447: growth, biofilm formation, exopolysaccharide production, and cell membrane permeability
}

\author{
Hafidha KhadeM ${ }^{1,2}$ *, Aicha Meddah Tirtouil ${ }^{1}$, Moustapha Soungalo Drabo ${ }^{3}$, Badra Boubakeur ${ }^{1,2}$ * \\ ${ }^{1}$ A Bioconversion Laboratory, Microbiology Engineering and Health Safety, \\ Faculty of Nature and Life Sciences, University Mustapha Stambouli of Mascara, Algeria \\ ${ }^{2}$ Ibn Khaldoun University, Tiaret, Algeria \\ ${ }^{3}$ University Joseph Ki-Zerbo, Ouagadougou, Burkina Faso
}

\begin{abstract}
Sonication is one of the new and innovative approaches that is being increasingly used in food industry to control fermentation processes and to eradicate spoiling. Recently, this approach has seen new industrial applications such as enhancing microbial productivity. The present study aimed to assess the effects of ultrasound conditioning on the metabolism and extracellular matrix production of Streptococcus thermophilus. Bacterial suspensions were treated in ultrasonic bath $(35 \mathrm{kHz}, 240 / 60 \mathrm{~W}$ peak/nominal power, 1.81 capacity) for different time periods $(5,10,15,20,30,45$, and $65 \mathrm{~min})$, and the growth improvement, adhesion ability, biofilm formation, and exopolysaccharide production of the bacterial strain were measured. The bacterial strain exhibited resistance to the treatment, and the conditioning improved the growth, adhesion, membrane permeability, biofilm formation, and exopolysaccharide production ability. An optimal treatment was obtained for 30 minutes of conditioning. An excellent yield of desirable exopolysaccharides (1788 mg glucose equivalent/l) was achieved. Ultrasound conditioning may be used as a potential approach to enhance certain biotechnological properties of industrial microorganisms.
\end{abstract}

Key words: Streptococcus thermophilus, ultrasound conditioning, bacterial adhesion, biofilm, exopolysaccharides

\section{Introduction}

Lactic acid bacteria (LABs) are a group of microorganisms that are generally recognized as safe (GRAS) and are highly used in biotech industry (such as cell reactors) and healthcare (such as probiotics). They are ranked second after yeasts as the most valued microbial bioresource for humans (Xiao et al., 2014). For instance, LABs were first used for fermentation in dairy industry, and their use is related to their ability to transform basic milk to high-grade products such as yogurt, cheese, ice cream, and kefir. The principal qualities of dairy products are preservation from spoiling, organoleptic properties, and texturing/rheological properties (Novel, 1993; Mozzi et al., 1996). In addition, contemporary consumers are increasingly anxious about the health-related properties of food and are raising concerns for safety and probiotic properties of dairy products. Because of their beneficial uses, LABs are widely considered in mainstream research, and many efforts have been made to improve their functional properties. The most investigated properties are their benefits to human health as probiotics and their industrial performance as cell reactors (Burgain et al., 2011).

Probiotic properties imply the ability of the microorganisms to tolerate digestive tract conditions, to nest in (at least for some time), to compete (through either production of antimicrobial or outgrowth against pathogens), and/or to improve digestion and nutrition (FAO/WHO, 2001; Boubakeur et al., 2018). Biofilm is a physiological state of microorganisms that exhibits

\footnotetext{
* Corresponding author: A Bioconversion Laboratory, Microbiology Engineering and Health Safety, Faculty of Nature and Life Sciences, University Mustapha Stambouli of Mascara, Algeria; Ibn Khaldoun University, Tiaret, Algeria; e-mail: boubakeurbadra82@yahoo.fr; hafidha.khadem@univ-mascara.dz
} 
specific traits, including improving adhesion ability and production of exopolysaccharides (EPS). Adhesion ability is an important characteristic that facilitates probiotic nesting in the mucous membranes of the digestive tract (FAO/WHO, 2001; O'Grady and Gibson, 2005). EPS are biomolecules belonging to the class of dietary fibers, which are known for their health effects as prebiotics and shield for the microorganisms against the adverse gastric environment (Caggianiello et al., 2016; London et al., 2016). In addition, these microbial metabolites exhibit antispoiling, rheological, and textural properties in milk products (Patel et al., 2012). However, only few dairy fermentative microorganisms can efficiently produce these multifunctional molecules, and the highest production yield currently reported is $3 \mathrm{~g} / 1$ (Welman and Maddox, 2003). For instance, the most efficient dairy fermentative bacteria Streptococcus thermophilus (S. thermophilus) can yield only 1-2 g/l (Wu et al., 2014; Kanamarlapudi and Muddada, 2017).

Many strategies have been investigated to enhance microbial biosynthesis. These strategies include improvements of the culture media and conditions (i.e., temperature, pressure, $\mathrm{pH}$, shear stress, and oxygen supply). The use of ultrasound is an emerging technology in biotech industry to improve microbial performance (Christi, 2003; Shikha et al., 2016). Ultrasounds are human-inaudible sound waves (frequencies superior or equal to $20 \mathrm{kHz}$ ) that can interfere mechanically and chemically with cell structure, metabolism, and physiology (Leighton, 2007). Few research studies have focused on investigating microbial conditioning by using this technology in terms of biofilm and EPS production capacities. In our previous study (Boubakeur et al., 2018), we reported interesting functional properties (prebiotic effects) of EPS of a local dairy starter isolate $S$. thermophilus. Therefore, with an interest in this microbial metabolite, the purpose of this study was to investigate the effects of ultrasound conditioning on biofilm formation, cell aggregation, EPS synthesis, and cell membrane permeability properties of the reference starter culture S. thermophilus CNRZ 447.

\section{Materials and methods}

\section{Bacterial suspension preparation}

The reference dairy starter culture $S$. thermophilus CNRZ 447 was obtained from INRA Rennes-France microbial collection. To assess the purity of the strain, it was grown aerobically on M17 agar (Pronadisa, Spain) at $42{ }^{\circ} \mathrm{C}$. An overnight grown new culture was always prepared on M17 agar for analysis. The colonies were picked with a Pasteur pipette and suspended in saline physiological water to optical density (OD) of $0.11\left(10^{8} \mathrm{CFU} / \mathrm{ml}\right)$ at $578 \mathrm{~nm}$ wavelength (BIOCHROM Libra S6).

\section{Ultrasound conditioning}

A series of glass test tubes were prepared, each containing $9 \mathrm{ml}$ of M17 broth (Pronadisa) and $1 \mathrm{ml}$ of $10^{8} \mathrm{CFU} / \mathrm{ml}$ S. thermophilus, and sonicated using the cavitation effect in Sonorex ultrasonic bath $(35 \mathrm{kHz}, 240 / 60 \mathrm{~W}$ peak/nominal powers, 1.81 capacity) (SONOREX TK 52). Briefly, the test tubes were placed in a porous rack and put in the sonicator tank. The tank was filled to the mark with 5\% Tickopur R 33 (Sigma-Aldrich), and the sonication was operated continuously. The time was measured with a chronometer, and duplicate tubes were withdrawn after $5,10,15,30,45$, and 65 minutes. The experiment was performed at room temperature of $25^{\circ} \mathrm{C}$.

\section{Survival and growth ability}

The sonicated bacterial suspensions were incubated at $42^{\circ} \mathrm{C}$ for $24 \mathrm{~h}$. Bacterial growth after the sonication treatments was subjectively assessed through OD measurement at $578 \mathrm{~nm}$ wavelength (BIOCHROM Libra S6). The OD reading was then converted to CFU $\log 10 / \mathrm{ml}$. The tolerance of the strain to sonication was also verified on agar plates.

\section{Biofilm quantification}

Microplate containing M17 broth was inoculated with the sonicated inocula and then incubated at $37^{\circ} \mathrm{C}$ for $24 \mathrm{~h}$ and the biofilm was quantified using the crystal violet staining method as described by O'Toole (2011). The stained biofilm was read at the determined optimal wavelength of $492 \mathrm{~nm}$ (ELx800TM Biotek microplate reader).

\section{Membrane permeability}

The cell membrane permeability was determined using the quantification of the leaked protein and nucleic acid according to Dai et al. (2016). The culture supernatant was collected by centrifugation at $3000 \mathrm{~g}$ for 20 minutes and subsequently diluted (1:9 v/v supernatant: distilled water). The extracellular proteins and 
nucleic acids were measured by absorbance (A) at 280 and 260 , respectively. The membrane permeability (P\%) was calculated using equation (1):

$$
\mathrm{P} \%=100 \times\left(\mathrm{A}_{\text {ultrasound }}-\mathrm{A}_{\text {without ultrasound }}\right) / \mathrm{A}_{\text {ultrasound }}
$$

\section{Autoaggregation ability}

The autoaggregation kinetics were measured according to Kos et al. (2003). The bacterial suspension was incubated for $18 \mathrm{~h}$ at $42^{\circ} \mathrm{C}$ and centrifuged at $5000 \mathrm{~g}$ for 15 minutes. The cell sediment was then washed twice with saline phosphate buffer (PBS) and dissolved again in PBS to achieve a cell concentration of $10^{7}$ to $10^{8}$ $\left(\mathrm{OD}_{0}=0.11\right.$ at $\left.578 \mathrm{~nm}\right)$. Subsequently, a $10 \mathrm{ml}$ aliquot was transferred into a glass test tube and isolated from shocks. The OD of the 1-2 cm upper layer of the suspension was monitored after $1,2,3$ and 4 hours $\left(\mathrm{OD}_{\mathrm{t}}\right)$. The autoaggregation percentage (A\%) was calculated using equation (2):

$$
\mathrm{A} \%=100 \times\left(1-\mathrm{OD}_{\mathrm{t}} / \mathrm{OD}_{0}\right)
$$

\section{EPS production}

The ultrasonic-treated and nontreated bacterial suspensions in M17 broth were grown for $18 \mathrm{~h}$ at $42^{\circ} \mathrm{C}$. The EPS were released using a thermal shock in water bath $\left(80^{\circ} \mathrm{C}\right.$ for 15 minutes) and ethanol precipitation as described by Ricciardi et al. (2002).

\section{EPS HPLC-profiling}

The EPS of the isolate were HPLC-profiled using the Agilent LC 1260 - Refractive index detector system. The EPS were dissolved in $1 \mathrm{ml}$ of HPLC grade water (Sigma-Aldrich). Then, $100 \mu \mathrm{l}$ of the extract suspension was mixed with $200 \mu \mathrm{l}$ of $2 \mathrm{M} \mathrm{HCl}$ and sonicated for $45 \mathrm{~min}$ a $45^{\circ} \mathrm{C}$ bath and continuously vortexed. The acid-hydrolyzed EPS volume was made up to $1 \mathrm{ml}$ with the eluent $80 \%$ acetonitrile and $20 \%$ water (HPLC grade, Sigma-Aldrich). A volume of $300 \mu \mathrm{l}$ of crude extract was also mixed with the eluent. The extracts were filtered $(0.22 \mu \mathrm{m})$, and a volume of $10 \mu \mathrm{l}$ was injected. The crude and hydrolyzed extracts were analyzed on an Agilent Zorbax Carbohydrate analysis column $(4.6 \times 150 \mathrm{~mm}, 5 \mu \mathrm{m})$. The flow rate was $1.3 \mathrm{ml} /$ minute, and the operation temperature was $30^{\circ} \mathrm{C}$.

\section{EPS quantification}

Crude EPS extracts were quantified as glucose equivalent according to the phenol-sulfuric acid method (Dubois et al., 1956).

\section{Statistical analysis}

All the analyses were performed in duplicate and expressed as mean \pm standard deviation. ANOVA oneway and Tukey's HSD were performed with the significance level of 0.05 by using Statistical Package for Social Sciences (SPSS) 21.0.

\section{Results and discussion}

\section{Effect of ultrasound conditioning on growth}

The sonication effects on the growth ability of the model strain $S$. thermophilus CNRZ 447 is shown in Figure 1 . The species tolerated the sonication treatment for the duration below 30 minutes. For longer treatments (45 and 65 minutes), the sonication significantly affected the bacterial growth ability $(7.76 \log 10$ vs $8.55 \log 10$ and $7.66 \log 10$ vs $8.55 \log 10$, respectively) $(P<0.05)$, thus suggesting the destructive effect of the ultrasound treatment. In contrast, Nguyen et al. (2009) indicated that ultrasounds $(20 \mathrm{kHz})$ can have dual effects on bifidobacteria: a negative effect because of the reduction in the number of viable cells and a positive one because of the fact that broken or destroyed cells can provide essential nutrients and signaling molecules that can promote culture growth. In agreement with our results, low intensity ultrasounds and short exposition times (less than 30 minutes) were demonstrated to improve the growth ability of Lactobacillus helveticus PTCC 1332, Lactobacillus acidophilus PTCC 1643, Bifidobacterium longum FTDC 8943, B. longum FTDC 2113, and Lactobacillus caseiATCC 393 (Yeo et al., 2011; Hashemi et al., 2018). It could be interpreted that ultrasounds can interfere with bacterial metabolisms and conditions important for physiological effects (Christi, 2003; Leighton, 2007; Shikha et al., 2016). However, depending on the application conditions (time, viscosity of the media, potency, and frequency of the wave) of the sonication and the characteristics of the bacterial species (cellular wall structures), ultrasounds can have different consequences that are either deleterious or beneficial for the bacteria (Tabatabaie and Mortasavi, 2008; Kobayashi et al., 2009). Tabatabaie and Mortasavi (2008) showed that selected LABs could tolerate sonication at different intensities. According to Garcin et al. (2015), LABs are more resistant to high-power ultrasonic treatment than yeast cells and suggested that this is due to the differences in cell sizes-sensitivity to sonication is greater when 
the cell is larger. Even among bacteria, cell sizes seem to have an important contribution to resistance to sonication treatment, as observed with our laboratory experience on resistance of Lactobacillus bulgaricus and S. thermophilus strains (data not published).

\section{Effect of ultrasound conditioning on biofilm propensity}

The results of the biofilm propensity of the strain S. thermophilus CNRZ 447 are presented in Figure 2. Ultrasound conditioning improved the biofilm production ability of the strain for the treatment durations of $15,30,45$, and 65 minutes as compared to the control without sonication (OD $0.20,0.33,0.22$, and 0.25 , respectively vs 0.1 for control). The biofilm production declined significantly to approximately $24-33 \%$ after 45 and 65 minutes of sonication as compared to the conditioning time of 30 minutes. This observation could be associated with the destruction of the bacterial cells with prolonged sonication treatments (Fig. 1). Generally, ultrasounds are being used as a cleaning technology to eradicate unwanted microorganisms and biofilms causing contamination. Nonetheless, the treatment can be gauged to trigger a stimulatory effect. As shown in Figure 1 and Figure 2, ultrasounds can destroy bacterial cells, but they can also be considered as a stressing or an interfering agent that can stimulate biofilm formation (a sophisticated protection mechanism of bacteria). We identified an optimal ultrasound conditioning time (30 minutes) to stimulate biofilm formation by $S$. thermophilus CNRZ 477. To the best of our knowledge, there is no study on the biofilm stimulation effect of ultrasound on LABs. Because of the long domestication of the LABs, they have lost, in contrast to the pathogens, the ability to produce consistent biofilms (Couvigny et al., 2015). Here, we showed that the ultrasound technology can be used to stimulate biofilm formation, which can be valuable for industrial microorganisms such as LABs. The biofilm production capacity can enhance several performances of the microorganisms, including resistance to antimicrobial agents and some industrial operations steps (shears and $\mathrm{pH}$ ), the biosynthesis processes (extracellular compounds), and the probiotic properties (adhesion, colonization, and immunomodulatory effect) (Czaczyk and Myszka, 2011; Couvigny et al., 2015; Caggianiello et al., 2016).

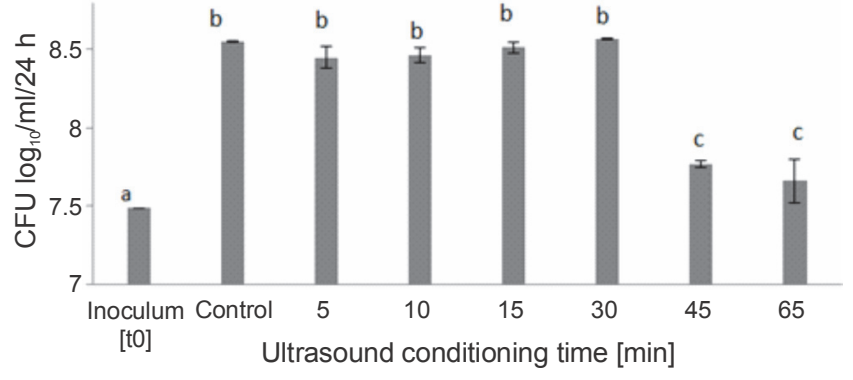

Fig. 1. Tolerance and growth ability of $S$. thermophilus CNRZ 447 as affected by ultrasound conditioning (values with different superscript letters $(\mathrm{a}, \mathrm{b}$, and $\mathrm{c}$ ) are significantly different, $P<0.05)$

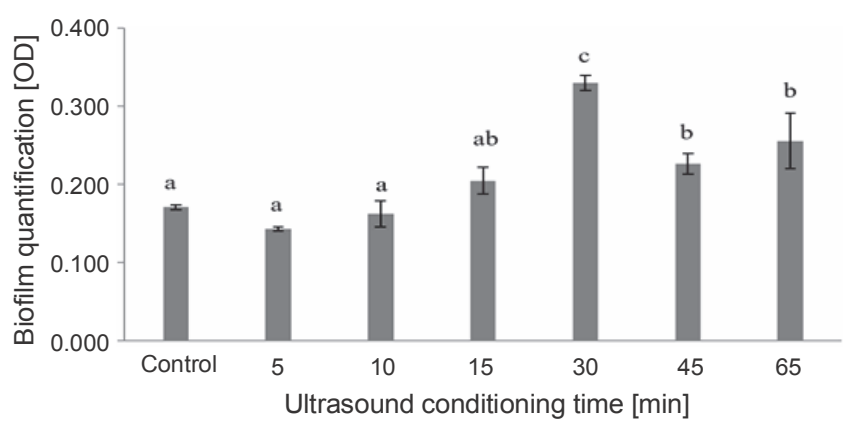

Fig. 2. Biofilm propensity of $S$. thermophilus CNRZ 447 as affected by ultrasound conditioning (values with different superscript letters (a, b, and c) are significantly different, $P<0.05$ )

\section{Effects of ultrasound conditioning on membrane permeability}

The precise mechanisms associated with biological activation with ultrasounds are still highly speculated. The most suggested mechanism is that the ultrasonic waves can induce microdiffusion, which can generate strong convection and improve substrate transfer (Christi, 2003; Leighton, 2007). Therefore, to understand the mechanochemical interferences of the ultrasounds that may have affected the strain's physiology, the protein and nucleic acid diffusion was assessed. The increase in the content of extracellular proteins and nucleic acids was $55 \pm 7.07 \%$ and $1.55 \pm 0.7 \%$, respectively. These results suggest that the ultrasounds had a low effect on nucleic acid diffusion but induced a high excretion of proteins, probably associated with the stimulation of protein synthesis and/or membrane permeability. The ultrasounds can effectively improve cell membrane permeability, facilitate the flow of nutrients and metabolites, and activate the metabolic processes 


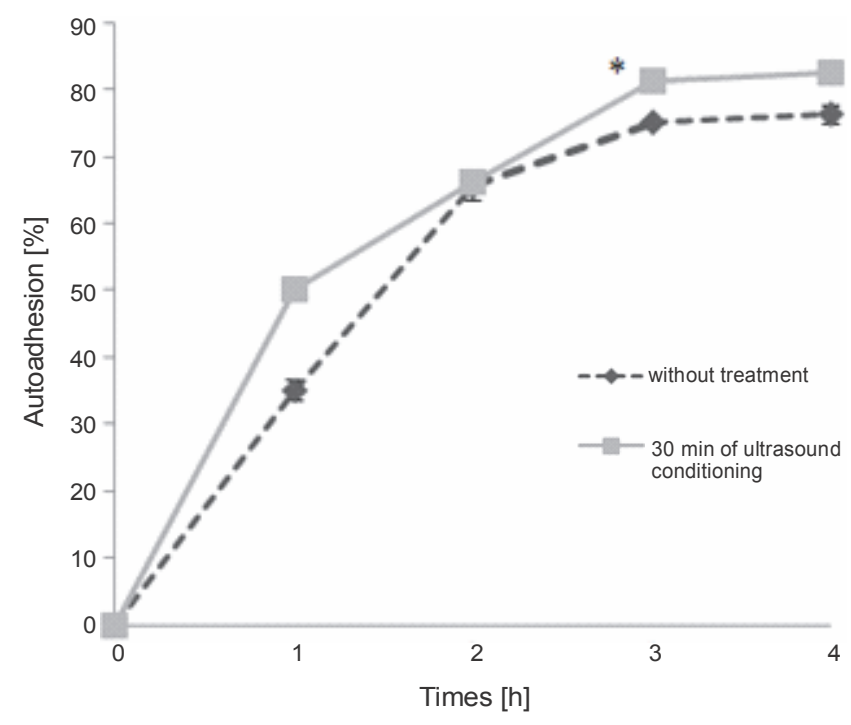

Fig. 3. Autoadhesion of $S$. thermophilus CNRZ 447 as affected by ultrasound conditioning ( ${ }^{*}$ indicates that the value is significantly different compared to the control without treatment $(0.05)$ )

(Pitt and Ross, 2003; Yang et al., 2010). The cell membrane permeability is associated with passive diffusion of the quorum-sensing protein signaling molecules that can explain the stimulation of biofilm formation (Kamaraju et al., 2011; Fitzgerald et al., 2018).

\section{Effects of ultrasound conditioning on autoaggregation}

Adhesion ability is a fundamental step for probiotics to exert their health effect on the host. Several molecules may be involved in this process, such as cell wall teichoic and lipoteichoic acids, peptides and proteins, peptidoglycans, and EPS (Sanchez et al., 2007). The autoaggregation kinetics of the ultrasound-conditioned cells were compared to those of the control cells, as shown in Figure 3. S. thermophilus CNRZ 447 exhibited strong autoaggregation ability (above $70 \%$ after 3 hours), which is consistent with previous observations suggesting that $S$. thermophilus species are known to have strong adhesion ability (above 50\%) (Leighton, 2007; Khalil, 2010; Tuncer and Tuncer, 2014). Ultrasound-conditioning (30 minutes treatment) significantly improved the adhesion capacity of the strain (to approximately $82 \%)(P<0.05)$. We did not find any study that has evaluated the effect of ultrasounds on the aggregation capacity of this strain to better understand the nature of the interactions between ultrasounds and the adhesive properties of the strain. However, it could be inferred that the ultrasound can erode the surface structure of the cells and expose the adhesion molecules. Tabatabaie and Mortasavi (2008) showed that after an ultrasonic treatment $(20 \mathrm{kHz})$ with increasing duration, some proteins of the cell wall were activated and promoted good adhesion of the bacteria to surfaces.

\section{Effects of ultrasound conditioning on EPS production}

HPLC-profiling (Fig. 4) revealed that $S$. thermophilus CNRZ 447 EPS was mainly composed of two triholosides constituted mostly of glucose. The exact monosaccharide composition of the EPS was not adequately determined. Nonetheless, $S$. thermophilus species has been reported to produce heteropolysaccharides (Ricciardi et al., 2002; Kanamarlapudi and Muddada, 2017); however, the structural characterization of EPS of the $S$. thermophilus strains still needs further characterization. The present study showed that the $S$. thermophilus strain has important potential to produce EPS (Table 1). Ultrasound conditioning enhanced the metabolic activity of the strain and it outperformed EPS production (1745 mg glucose equivalent/ 1 vs $176 \pm 4 \mathrm{mg}$ glucose equivalent/l) for an optimal time of 30 minutes of sonication. Importantly, EPS production increased after 15 minutes of sonication but declined after 65 minutes ( $541 \pm 0.1 \mathrm{mg}$ glucose equivalent $/ 1$ and $83 \pm 3 \mathrm{mg}$ glucose equivalent/l, respectively). The decrease in EPS production after the prolonged sonication time might be explained by the deleterious effects of the treatment. Adequate time conditioning is thus essential for the use of ultrasound to improve the properties and performance of the beneficial microorganisms. Moncada and Aryana (2012) observed that low-potency sonication and controlled duration of exposure improve the desired properties of $S$. thermophilus, such as resistance to hostile gastrointestinal tract conditions (bile and $\mathrm{pH}$ ) and secretion of bioactive metabolites. The performance achieved was comparable to the maximum EPS yield of $S$. thermophilus species (1-2 g/l) (Wu et al., 2014; Kanamarlapudi and Muddada, 2017). In agreement with our previous study (Boubakeur et al., 2018), it was possible to improve EPS yield (from 200 to $826 \mathrm{mg}$ glucose/l, $P<0.05$ ) by conditioning $S$. thermophilus with polyphenol extract and to demonstrate their properties as prebiotics.

\section{Conclusions}

The present study reported the potential of sonication in improving bacterial metabolism, conditioning biofilm physiological traits, and enhancing EPS produc- 
A

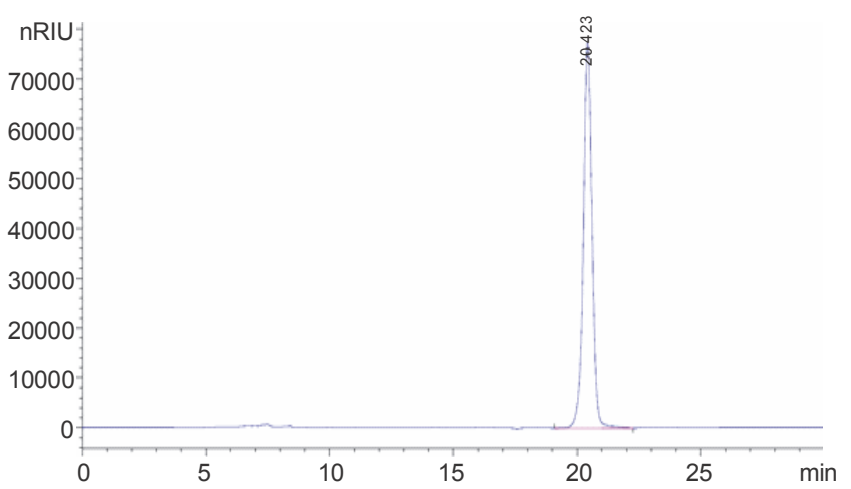

\section{B}

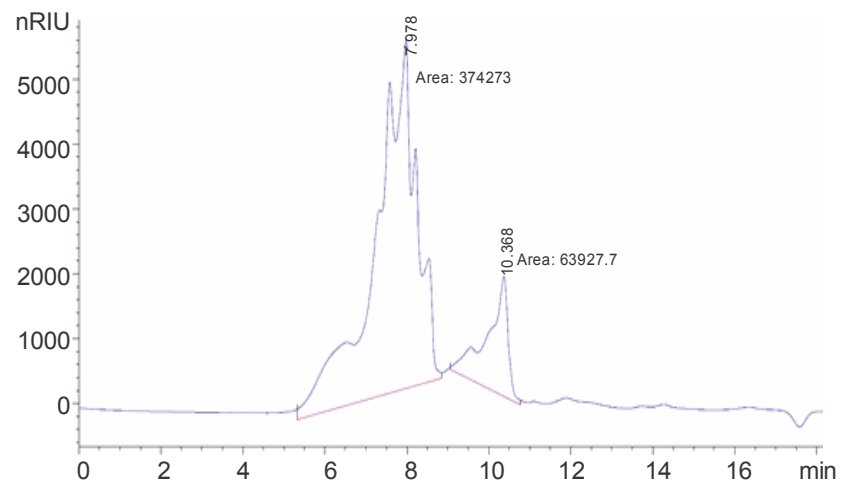

Fig. 4. HPLC-profiling of EPS of S. thermophilus CNRZ 447: A) A unique characteristic peak was observed in the EPS hydrolysis at 20.4 minute; it was identified as glucitol, which suggests that, B) the EPS is composed of at least two distinct triholosides (between 7 and 10 minutes) that are constituted of mainly glucose residues

Table 1. EPS productivity of $S$. thermophilus CNRZ 447 as affected by ultrasound conditioning

\begin{tabular}{l|c|c|c|c}
\hline Time [min] & Control & $15 \mathrm{~min}$ & $30 \mathrm{~min}$ & $65 \mathrm{~min}$ \\
\hline EPS [mg glucose/1] & $176 \pm 4^{\mathrm{a}}$ & $541 \pm 0.1^{\mathrm{b}}$ & $1745 \pm 12^{\mathrm{c}}$ & $83 \pm 3^{\mathrm{d}}$ \\
\hline
\end{tabular}

Values with different superscript letters (a, b, c, and d) are significantly different $(P<0.05)$

tion of a potential dairy starter and probiotic strain. There is increasing interest in the health-promoting properties of probiotics and their EPS. Physical conditioning techniques such as ultrasound should be further explored and used to enhance the properties of beneficial microorganisms.

\section{Acknowledgments}

The authors express their gratitude to Algeria Ministry of Higher Education and Scientific Research and to the General Directorate for Scientific Research and Technological Development for the $\mathrm{PhD}$ grant.

\section{References}

Boubakeur B., Drabo M.S., Khadem H., Mullier C., Tirtouil A. (2018) Influence of the exopolysaccharides of polyphenolsconditioned lactic acid bacteria on gut microecology and bacterial translocation. Ukr. J. Ecol. 18: 1-9.

Burgain J., Gaiani C., Linder M., Scher J. (2011) Encapsulation of probiotic living cells: From laboratory scale to industrial applications. J. Food. Eng. 104: 467-483.

Caggianiello G., Kleerebezem M., Spano G. (2016) Exopolysaccharides produced by lactic acid bacteria:from healthpromoting benefits to stress tolerance mechanisms. Appl. Microbiol. Biotechnol. 100: 3877-3886.

Christi Y. (2003) Sonobioreactors: Using ultrasound for en hanced microbial productivity. Trends Biotechnol. 21: 89-93.
Couvigny B., Thérial C., Gautier C., Renault P., Briandet R., Guédon E. (2015) Streptococcus thermophilus biofilm formation: a remnant trait of ancestral commensal life? PLOS One. 10: 1-23.

Czaczyk K., Myszka K. (2011) Biofilms in the food environment. [in:] Encyclopedia of agrophysics. Ed. Gliński J., Horabik J., Lipiec J. Netherlands, Springer: 76-78.

Dai C., Xiong F., He R., Zhang W., Ma H. (2016) Effects of low-intensity ultrasound on the growth, cell membrane permeability and ethanol tolerance of Saccharomyces cerevisiae. Ultrason. Sonochem. 36: 191-197.

Dubois M., Gilles K.A., Hamilton J.K., Rebers P.A., Smith F. (1956) Colorimetric method for determination of sugars and related substances. Anal. Chem. 28: 350-350.

FAO/WHO (2001) Health and nutritional properties of probiotics in food including powder milk with live lactic acid bacteria. Report of a joint FAO/WHO expert consultation.

Fitzgerald N.J.M., Simcik, M.F., Novak, P.J. (2018) Perfluoroalkyl substances increase the membrane permeability and quorum sensing response in Aliivibrio fischeri. Environ. Sci. Technol. Lett. 5: 26-31.

Garcin L., Jambrak A.R., Juretić H., Dobrović S., Barukčić I., Grozdanović M., Smoljanić G. (2016) Influence of high power ultrasound on Brettanomyces and lactic acid bacteria in wine in continuous flow treatment. Appl. Acoust. 103B: 143-147.

Hashemi S.M.B., Mousavi Khaneghah A., Saraiva J.A., Jambrak A.R., Barba F.J., Mota J.M. (2018) Effect of ultrasounds on lactic acid production by Lactobacillus strains in date (Phoenix dactylifera var. kabkab) syrup. Appl. Microbiol. Biotechnol. 102: 2635-2644. 
Kamaraju K., Smith J., Wang J. (2011) Effects on membrane lateral pressure suggest permeation mechanisms for bacterial quorum signaling molecules. Biochemistry 50: 6983-6993.

Kanamarlapudi S.L.R.K., Muddada S. (2017) Characterization of exopolysaccharide produced by Streptococcus thermophilus CC30. Biomed. Res. Int. 2017: 1-11.

Khalil R.K.S. (2010) Influence of gallic acid and catechin polyphenols on probiotic properties of Streptococcus thermophilus CHCC 3534 strain. World J. Microbiol. Biotechnol. 26: 2069-2079.

Kobayashi Y., Sakai D., Iwashina T., Iwabuchi S., Mochida J. (2009) Low-intensity pulsed ultrasounds stimulates cell proliferation, proteoglycan synthesis and expression of growth factor-related genes in human nucleus pulposus cell. Eur. Cell Master. 17: 15-22.

Kos B., Suskovic J., Vukovic S., Simprag M., Frece J., Matosic S. (2003) Adhesion and aggregation ability of probiotic strain Lactobacillus acidophilus M92. J. Appl. Microbiol. 94: 981-987.

Leighton T.G. (2007) What is ultrasound?. Prog. Biophys. Mol. Biol. 93: 3-83.

London L.E.E., Ross R.P., Fitzgerald G.F., Shanahan F., Caplice M.N., Stanton C. (2016) Probiotics as cell factories for bioactive ingredients: focus on microbial polysaccharides and health beneficial effects. [in:] Advances in probiotic technology. Ed. Foerst P., Santivarangkna C., Boca Raton, Taylor and Francis Group: 77-103.

Moncada M., Aryana K.J. (2012) Influence of "mild" sonication conditions on the characteristics of Streptococcus thermophilus ST-M5. Adv. Microbiol. 2: 8-16.

Mozzi F., Savoy de Giori G., Oliver G., Font de Valdez G. (1996) Exopolysaccharide production by Lactobacillus casei in milk under different growth conditions. Milchwissenschaft. 51: 670-673.

Novel G. (1993) Les bactéries lactiques. [in:] Microbiologie industrielle, les microorganismes d'intérêt industriel. Ed. Leveau J.Y, Bouix M., Paris, Tec et Doc Lavoisier: 170-331.

Nguyen T.P., Lee Y.K., Zhou W. (2009) Stimulating fermentative activities of bifidobacteria in milk by high intensity ultrasounds. Int. Dairy J. 19(6-7): 410-416.

O'Grady B and Gibson G.R. (2005) Microbiota of the human gut. [in:] Probiotic dairy products. Ed. Tamime A., Oxford, Blackwell Publishing Ltd: 1-20.

O’Toole G.A. (2011) Microtiter dish biofilm formation assay. J. Vis. Exp. 47: 1-3.
Patel S., Majumder A., Goyal A. (2012) Potential of exopolysaccharides from lactic acid bacteria. Indian J. Microbiol. 52: 3-12.

Pitt W., Ross G.S.A. (2003) Ultrasounds increase the rate of bacterial cell growth. Biotechnol. Prog. 19: 1038-1044.

Ricciardi A., Parente E., Crudele M.A., Zanetti F., Scolari G., Mannazzu I. (2002) Exopolysaccharide production by Streptococcus thermophilus SY: production and preliminary characterization of the polymer. J. Appl. Microbiol. 92: 297-306.

Sanchez B., Champomier-Verges M.C., Collado M.D.C., Anglade P., Baraige, F., Sanz Y., De Los Reyes-Gavilan C.G, Margolles A., Zagorec M. (2007) Low-pH Adaptation and the acid tolerance response of Bifidobacterium longum biotype longum. Appl. Environ. Microbiol. 73: 6450-6459.

Shikha O.K., Donnell P.O., Colm J.C., Brijesh K.T. (2016) Ultrasounds and food fermentation. [in:] Novel food fermentation. Ed. Shikha Ojha K and Brijesh Tiwari K., Switzerland, Springer International Publishing: 125-142.

Tabatabaie F., Mortazavi A. (2008) Studying the effects of ultrasounds shock on cell wall permeability and survival of some LAB in milk. World Appl. Sci. J. 3: 119-121.

Tuncer B.O., Tuncer Y. (2014) Exopolysaccharide producer Streptococcus thermophilus st8.01 strain; a potential probiotic culture. GIDA. 39: 195-202.

Welman A.D., Maddox I.S. (2003) Exopolysaccharides from lactic acid bacteria:perspectives and challenges. Trends Biotechnol. 21: 269-274.

Wu Q., Tun M.H., Leung F.C., Shah N.P. (2014) Genomic insights into high exopolysaccharide-producing dairy starter bacterium Streptococcus thermophilus ASCC 1275. Sci. Rep. 15: 49-74.

Xiao J., Zhang Y., Yang Z. (2014) Genomic of lactic acid bacteria. [in:] Lactic acid bacteria fondamental and practis. Ed. Zang H., Cai Y., Dordlecht, Springer : 250-303.

Yang S., Zhang H., Wang W. (2010) The ultrasonic effect on the mechanism of cholesterol oxidase production by Brevibacterium sp. Afr. J. Biotechnol. 9: 2574-2578.

Yeo S.K., Liong M.T. (2011) Effect of ultrasounds on the growth of probiotics and bioconversion of isoflavones in prebiotic-supplemented soymilk. J. Agric. Food Chem. 59: 885-897. 